\title{
EFFECT OF ARTIFICIALLY ACCELERATED AGEING AND DIFFERENT MOUTH RINSES ON COLOR STABILITY OF VENEERED PEEK CROWNS
}

\author{
Ahmed Ziada * and Marwa Beleidy**
}

\begin{abstract}
Statement of problem: Veneered polyether ether ketone (PEEK) is a recent alternative choice for fixed dental prostheses. There is a lack of data about the color stability of veneered CAD/CAM PEEK crowns using different veneering composite techniques.

Purpose: To verify the effect of thermocycling and different mouth rinses on color stability of $\mathrm{CAD} / \mathrm{CAM}$ composite versus conventional nanohybrid composite veneered PEEK crowns.

Methods: Forty-two duplicated epoxy resin dies of prepared mandibular first molar to receive a ceramic crown were fabricated. 42 CAD/CAM PEEK cores were fabricated and divided into two groups ( $n=21)$ based on the veneering technique; group (C): nanohybrid crea.lign composite veneered PEEK cores (control) and group (H): HIPC veneered PEEK cores. Each group was further subdivided based on the mouth rinse into 3 groups ( $n=7)$ : Listerine-alcohol free, Hexitol and Distilled Water (control). The color at baseline, after thermocycling equivalent to clinical 6 months service and 1-week immersion in mouth rinses were measured utilizing a spectrophotometer. The data were statistically analyzed using ANOVA, pair-wise Tukey's post-hoc and student t-tests to reveal the significance between groups $(\mathrm{P} \leq 0.05)$.
\end{abstract}

Results: All specimens showed visually unperceptible color differences after thermocycling and immersing in mouth rinses $\left(\Delta \mathrm{E}^{*}<3.3\right)$. Based on material, $\mathrm{C}$ group showed statistically significant higher color change values than $\mathrm{H}$ group. ANOVA test revealed that the highest color change was for Hexitol followed by Listerine then Distilled Water $(\mathrm{p}=<0.0001<0.05)$. Tukey's post-hoc test showed a non-significant difference between Hexitol and Listerine. The interaction between the effect of mouth rinses and type of veneering composite materials was statistically non-significant for $\mathrm{C}$ group $(\mathrm{P}>0.05)$ while significant for $\mathrm{H}$ group $(\mathrm{P}<0.05)$.

Conclusions: Although visually nonperceptible, HIPC or nanohybrid composite veneered PEEK crowns showed a color difference after thermocycling and immersion in different mouth rinses.

KEYWORDS: HIPC, nanohybrid composite, PEEK, CAD/CAM, color stability and mouth rinse.

\footnotetext{
* Lecturer, Department of Fixed Prosthodontics, Faculty of Dentistry, Benisuef University, Benisuef, Egypt.
}

** Lecturer, Department of Fixed Prosthodontics, Faculty of Dentistry, October 6th University, Giza, Egypt. 


\section{INTRODUCTION}

Polyether ether ketone (PEEK) is introduced in the dentistry as a revolutionary material of choice for fixed and removable prostheses due to its promising mechanical and biological behaviors which arise from the chemical composition nature. ${ }^{1}$ It was found that it met the needed requirements for the restorative field on the basis of mechanical stability and bonding to veneering materials. ${ }^{2,3}$ The veneering is a prime concern when restoring with PEEK material due to its low translucency and grayish white color that affect the esthetic outcomes and make its use as a monolithic restorative material questionable, especially if the intended area is the esthetic zone.

Oral environment plays a rule in the performance of the veneering materials through two main pathways: the first pathway is the extrinsic coloring of the consumed food like caffeine, acidic rich products or mouth rinses where the chemical adhesion results in their discoloration effect. The second pathway is the intrinsic factors related to ageing, genetics and processing moods of placed restorations ${ }^{4-7}$ Therefore, further investigations on the color stability of veneered restorations are still needed.

Several tools as spectrophotometers, calorimeters and digital cameras were used to detect the color. Spectrophotometric technology is widely used in dental color studies due to its optimal and accurate technique for qualitative color analysis. ${ }^{8}$

To date, according to the authors' knowledge, there is a shortage in the available findings about the color stability performance of CAD/CAM PEEK substructures veneered with composite resins after thermocycling and immersion in different mouth rinse solutions. Therefore, the aim of the study was to examine the color stability of two differently manufactured composite resins veneering CAD/ CAM PEEK substructures after their interactions with thermocycling and different mouth rinses. The null hypothesis of the current research was that the thermocycling and mouth rinses would have no effect on the color stability of differently veneered PEEK crowns.

\section{MATERIALS AND METHODS}

\section{Sample size calculation}

To determine large effect sizes for the main effects and pair-wise comparisons, sample size was calculated to be 7 specimens per a tested group that was large enough. $80 \%$ power and $95 \%$ confidence levels were set.

\section{Preparation of specimens}

A preparation for an all ceramic crown was performed to a typodont mandibular first molar tooth. The preparation guidance included $12^{\circ}$ total convergence angle, $1.0 \mathrm{~mm}$ deep chamfer margin circumferentially, $1.5 \mathrm{~mm}$ anatomical occlusal preparation, $1.5 \mathrm{~mm}$ axial preparation and $3.0 \mathrm{~mm}$ preparation height. All sharp points and line angles were rounded off. 9 It was then replicated to have 42 dental epoxy resin dies ${ }^{10}$ to receive two types of veneered CAD/CAM PEEK crowns. Each prepared die was scanned using 3D dental scanner (Identica hybrid; MEDIT corp., Seoul, Korea). Forty-two cores were designed (exocad Dental CAD; exocad $\mathrm{GmbH}$, Germany) and milled (K5; vhf camfacture AG, Germany) from PEEK blanks (breCAM. BioHPP Discs; Bredent, Senden, Germany, LOT: 400177). The core thickness was set at $0.5 \mathrm{~mm}$, while the cement space was set at $50 \mu \mathrm{m}$. The cores were then sandblasted (basic Quattro IS; Renfert, Hilzingen, Germany) using $110 \mu \mathrm{m} \mathrm{Al}_{2} \mathrm{O}_{3}$ particles at $0.25 \mathrm{Mpa}$ and $45^{\circ}$ direction with $10 \mathrm{~mm}$ distance. After the air abrasion process, the cores were drowned for 5 minutes into ultrasonic bath (L\&R Transistor Ultrasonic T14, L\&R, Kearny, NY, USA). Afterwards, the PEEK cores were treated by visio.link (Bredent, Senden, Germany; LOT: 141432) where a thin coat was applied and 90 seconds polymerization was done (intensity: $220 \mathrm{~mW} / \mathrm{cm}^{2}$, Brelux Power Unit; bredent Senden, 
Germany). Then, a thin film application of the opaquer composite (Opaker combo.lign; shade A3, bredent, Senden, Germany) was done, followed by 360 seconds polymerization.

The specimens then were grouped into two groups ( $n=21 /$ group) in accordance with the veneering technique: (Group: C) veneered with conventional veneering nanohybrid composite resin, crea. lign (shade A3, bredent Senden, Germany; Lot No. 130513) as a control group and (Group: $\mathrm{H}$ ) veneering with digital CAD/CAM breCAM, HIPC (shade A3, bredent, Senden, Germany; Lot No. 406700),

For conventional nanohybrid composite resin veneering group, a mold of transparent silicone (visio.sil; bredent Senden, Germany) for a waxed up master crown was made and filled with crea.lign composite resin. Then, the epoxy resin die with the attached PEEK core was pressed into the silicone mold and the polymerization was carried out for 360 seconds. The obtained crown was then polished (Opal L, Renfert GmbH, Hilzingen, Germany; Lot No. 520-0001; Abraso Starglanz; bredent, Senden, Germany).

For the digital veneered group, two scans (Identica hybrid; MEDIT corp., Seoul, Korea) were carried out, one for the PEEK core on the epoxy resin die and one more for the master crown on the same die which then subtracted from each other to have the digital veneer design as the thickness was set at $1.0 \mathrm{~mm}$ followed by milling (K5; vhf camfacture AG, Germany) from breCAM.HIPC blanks. The veneers then were dissembled and the mill connectors were removed. Sandblasting of each veneer's inner surface was done (basic Quattro IS; Renfert, Hilzingen, Germany) using $\mathrm{Al}_{2} \mathrm{O}_{3}$ powder of $110 \mu \mathrm{m}$ particles size at $0.25 \mathrm{MPa}$, a $45^{\circ}$ angle and $10 \mathrm{~mm}$ distance, and later immersed for 5 minutes in an ultrasonic bath (L\&R Transistor Ultrasonic T14, L\&R, Kearny, NY, USA). After the inner surface was dried, visio.link (bredent, Senden, Germany; LOT: 141432) was applied and let to polymerize for 90 seconds. The manufactured cores were placed on their corresponding epoxy resin dies. The veneers were filled with combo. lign (shade A3, bredent Senden, Germany; Lot No. 132420) before pressing them on the cores utilizing a device delivering a uniform load of $5 \mathrm{~kg}(49 \mathrm{~N})$ for 10 minutes. Then, 180 seconds of polymerization was performed with $220 \mathrm{~mW} / \mathrm{cm}^{2}$ (brelux Power Unit; bredent Senden, Germany). Each crown was then polished after removing the excess as same as described previously.

\section{Color Stability Determination}

\section{Baseline color measurements}

For each specimen, a baseline color was measured utilizing a reflective spectrophotometer (X-Rite, model RM200QC, Neu-Isenburg, Germany). $4 \mathrm{~mm}$ aperture size was set with exactly aligned specimen to centralize the device measurement tip in relation to the tested specimen where a white background and standard illuminant D65 were selected. The measurements were based on Commission Internationale de l'Eclairage (CIE) $L^{*} a^{*} b^{*}$ color space mathematic coordinates which are for lightness/luminosity, namely white-black $\left(\mathrm{L}^{*}\right)$, redness-green $\left(\mathrm{a}^{*}\right)$, and yellowness-blueness $\left(b^{*}\right)$. Three labial surface readings were taken and the average $L^{*}, a^{*}$, and $b^{*}$ values were calculated and tabulated as measurements of the baseline color.

\section{Thermocycling}

All tested specimens were thermocycled in a thermocycling machine (MPC, ElQuip, São Carlos, SP, Brazil) for 5000 thermocycles equivalent to 6 months clinical service. ${ }^{11}$ Each cycle consisted of $5^{\circ} \mathrm{C}$ and $55^{\circ} \mathrm{C}$ water baths, 30 seconds dwell time and 7 seconds transfer time.

\section{Post-thermocycling color measurements}

Using the identical spectrophotometer and conditions, the color measurements were recorded as described for the baseline measurements. $\Delta \mathrm{E}_{\mathrm{CIELAB}}=$ $\left(\Delta \mathrm{L}^{* 2}+\Delta \mathrm{a}^{* 2}+\Delta \mathrm{b}^{* 2}\right)^{1 / 2}$ was the used formula to calculate the color change $\left(\Delta \mathrm{E}^{*}\right)$ between the two color positions (after thermocycling and baseline) in $3 \mathrm{D} \mathrm{L} * \mathrm{a} * \mathrm{~b}^{*}$ color space. ${ }^{12}$ 
TABLE (1) Chemical compositions of the mouth rinses.

\begin{tabular}{|c|c|c|c|}
\hline Mouth rinse & Manufacturer & Chemical composition & pH \\
\hline $\begin{array}{l}\text { Listerine Zero } \\
\text { Mouthwash } \\
\text { Mild Mint }\end{array}$ & $\begin{array}{l}\text { Johnson \& Johnson Limited, } \\
\text { Maidenhead, SL6 3UG, UK }\end{array}$ & $\begin{array}{l}\text { Eucalyptol, Thymol, Menthol, Sodium lauryl Sulfate, } \\
\text { Aroma, Benzoic Acid, Methyl Salicylate, Poloxamer } \\
\text { 407, Propylene Glycol, Sodium Benzoate, Sodium, } \\
\text { Saccharin, Sorbitol, Sucralose, Water, Cl 42053, Sodium } \\
\text { Fluoride }(0.0220 \%)\end{array}$ & 3.7 \\
\hline Hexitol & $\begin{array}{l}\text { Arab Drug Company } \\
\text { (ADCO), Cairo, Egypt }\end{array}$ & $\begin{array}{l}\text { 125mg/100ml chlorhexidine HCl, Glycerin, Propylene } \\
\text { Glycol, Alcohol 96\%, Anise Oil, Peppermint Red, } \\
\text { Cremophor, RH 40, Purified Water. }\end{array}$ & 5.8 \\
\hline
\end{tabular}

\section{Mouth rinse solutions}

Three mouthrinse solutions were used in this study (table 1): group 1 (Listerine Zero Mouthwash Mild Mint; Johnson \& Johnson Limited, Maidenhead, SL6 3UG, UK), group 2 (Hexitol; Chlorhexidine HCL 125mg/100 ml, Arab drug company, Cairo, Egypt) and group 3 (Distilled Water-control). To stimulate the oral cavity conditions, each mouth rinse was kept in a dark environment at $37^{\circ} \mathrm{C} \pm 1^{\circ} \mathrm{C}$. During the whole study time (one week), the mouth rinse solutions were changed every 12 hours. After 7 days of crowns' immersing, the distilled water was used to rinse specimens for 5 minutes, and then a tooth paste (Colgate-Palmolive Arabia L.T.D, Damam, KSA) and a soft brush (Oral-B, Procter \& Gamble UK, Weybridge, Surrey, KT13 0XP, UK) were used to gently brush the specimens for 15 seconds. Finally, the specimens were dried using tissue papers before the third color measurement.

\section{Post-mouth rinses immersion color measurements}

The same protocol of the baseline color measurement was used. The color change $\left(\Delta \mathrm{E}^{*}\right)$ between the two-color positions (after one-week storage and baseline) in 3D L*a*b* color space was calculated. ${ }^{12}$ Clinically unacceptable color change would be $>3.3 .{ }^{13}$

\section{Statistical analysis}

Mean and standard deviations were used to express the variables. After confirming the homogeneity of variance and the normal distribution of errors, two-way analysis of variance ANOVA was performed. One-way ANOVA test was utilized for comparison among different mouth rinse subgroups followed by Tukey's pairwise (if ANOVA showed a significance) and student t-test for comparison between the material groups interactions. The statistical significance was considered at a value of $\mathrm{P}<0.05$ with $80 \%$ power and $95 \%$ confidence levels. The received data were analyzed using a software for windows (GraphPad Instat 3.1; GraphPad Software, CA, USA).

\section{RESULTS}

\section{Color change after thermocycling}

As a function of thermocycling, $\mathrm{C}$ group showed statistically a non-significant higher change mean value $(0.98 \pm 0.16 \Delta \mathrm{E})$ than $\mathrm{H}$ group $(0.93 \pm 0.182$ $\Delta \mathrm{E})$ as revealed by t-test $(\mathrm{p}=0.4045>0.05)$ in table (2). 
TABLE (2) Color change results (Mean \pm SD) for crea.lign and HIPC veneered PEEK crown groups as a function of thermocycling from baseline.

\begin{tabular}{cccc}
\hline \multirow{2}{*}{$\begin{array}{c}\text { Material } \\
\text { group }\end{array}$} & $\begin{array}{c}\text { Color change }(\Delta \mathrm{E}) \\
\text { after thermocycling }\end{array}$ & \multicolumn{2}{c}{ Statistics } \\
\cline { 2 - 4 } & Mean \pm SD & t-value & P value \\
\hline C group & $0.98 \pm 0.16$ & 0.85 & $0.4045 \mathrm{~ns}$ \\
\hline H group & $0.93 \pm 0.18$ & & \\
\hline
\end{tabular}

ns: non-significant.

\section{Color changes after mouth rinses immersion}

As function of mouth rinse solutions in $\mathrm{C}$ group, Listerine subgroup (Group: C1) recorded the highest color change mean values followed by Hexitol subgroup (Group: C2), while the lowest color change mean values were for Distilled Water immersed subgroup (Group: C3). The difference between mouth rinses groups was statistically nonsignificant as indicated by one-way ANOVA test $(\mathrm{p}=0.1439>0.05)$ as shown in table (3).

While in $\mathrm{H}$ group, Hexitol subgroups (Group: H2) recorded the highest color change mean values followed by Listerine subgroup (Group: H1), while the lowest color change mean values were for Distilled Water subgroup (Group: H3).
The difference between mouth rinse groups was statistically significant as revealed by one-way ANOVA followed by pair-wise Tukey's post-hoc tests $(\mathrm{p}=<0.0001<0.05)$ as shown in table (3).

\section{C group versus $\mathrm{H}$ group}

$\mathrm{H}$ group recorded statistically a non-significant higher color change mean value than $\mathrm{C}$ group after immersion in Hexitol as proved by student t-test $(\mathrm{p}=0.6291>0.05)$. While $\mathrm{C}$ group recorded statistically a significant higher color change mean value than $\mathrm{H}$ group after immersion in Listerine or Distilled Water as demonstrated by student t-test $(\mathrm{p}=0.0476<0.05)(\mathrm{p}=<0.0001<0.05)$.

Regardless of mouth rinse solution, $\mathrm{C}$ group showed statistically a significant higher color change mean value than $\mathrm{H}$ group as indicated by two-way ANOVA test $(\mathrm{p}=<0.0001<0.05)$.

Irrespective of material group, Hexitol subgroups recorded the highest color change mean values followed by Listerine subgroups while the lowest color change mean values were for Distilled Water subgroups. The difference between material groups was statistically significant as revealed by two-way ANOVA test $(\mathrm{p}=<0.0001<0.05)$. Pair-wise Tukey's post-hoc test showed a non-significant difference between Hexitol and Listerine subgroups.

TABLE (3) Color change results (Mean \pm SD) for crea.lign and HIPC veneered PEEK crown groups as a function of different mouth rinse solutions.

\begin{tabular}{|c|c|c|c|c|c|}
\hline \multirow{2}{*}{\multicolumn{2}{|c|}{ Material group }} & \multicolumn{3}{|c|}{ Mouth rinse solution $(\Delta \mathrm{E})$} & \multirow{2}{*}{$\begin{array}{c}\text { ANOVA } \\
\text { P value }\end{array}$} \\
\hline & & Hexitol & Listerine & Distilled Water & \\
\hline \multirow{2}{*}{ C group } & Mean & 1. $26^{\mathrm{A}}$ & $1.33^{\mathrm{A}}$ & $1.12^{\mathrm{A}}$ & \multirow{2}{*}{$0.1439 \mathrm{~ns}$} \\
\hline & SD & 0.17 & 0.24 & 0.13 & \\
\hline \multirow{2}{*}{ H group } & Mean & $1.30^{\mathrm{A}}$ & $1.1^{\mathrm{B}}$ & $0.90^{\mathrm{C}}$ & \multirow{2}{*}{$<0.0001 *$} \\
\hline & SD & 0.14 & 0.12 & 0.14 & \\
\hline Student t-test & P value & $0.6291 \mathrm{~ns}$ & $0.0476^{*}$ & $<0.0001^{*}$ & \\
\hline
\end{tabular}

letters in the same row indicating significant $(P<0.05)$.

*: significant $(P<0.05)$.

ns: non-significant. 


\section{DISCUSSION}

Due to the low translucency and grayish white color of PEEK which affect the esthetic outcomes and make its use as a monolithic restorative material questionable, using additional resin composite as a veneering layer is required. In addition, unanticipated color stability and susceptibleness to staining are two dominant obstacles for esthetic restorations. Therefore, several researches aiming to improve the materials and fabrication techniques were carried out.

Composite build up can be achieved by readymade veneers (eg: visio.lign), manual layering (eg; crea.lign paste), or CAD/CAM veneering composite (eg; HIPC composite blanks).

Hence the lighter shades of composites were found to be more subjected to color change, ${ }^{14}$ a universal shade $\mathrm{A} 3$ for the two veneering composite resin materials was selected. It was evidenced that composites tended to be significantly stained within the first week of exposure to staining solutions..$^{15,16}$ Therefore, 7 days immersion period was chosen.

Spectrophotometry was used for color measurement in the current study. ${ }^{17-21}$ Many studies demonstrated the instrumental reliability of the device. ${ }^{18,19,22,23}$ The accuracy of color measurement for translucent composites using an opaque standard for evaluation is not justified and the results theoretically could include bias. However, many researches have used this approach. ${ }^{21-29}$ White background was used in the present study as it has been utilized extensively as an approved background. ${ }^{18,21}$ In contrast, Ardu et al found that black backgrounds could be used as optimal backgrounds in comparison to grey and white ones. ${ }^{30}$

The CIELAB system was used in this study, hence color change was calculated by a special formula using the difference in $L^{*}, a^{*}, b^{*}$ values. ${ }^{19,20,31,32}$ It is important to differentiate between the color perception by the human eyes and the statistically accepted color difference, hence it is known that $\Delta \mathrm{E}$ below 1.1 is unperidectable by human eyes, while being above 3.3 is considered clinically unacceptable..$^{19,33,34}$

The null hypothesis of this study was accepted as thermocycling and different mouth rinse solutions had no negative effect on the color stability of the used veneering composite materials. The tested veneering composites in this study displayed acceptable color stability after thermocycling and after immersion in different mouth rinse solutions $\left(\Delta \mathrm{E}^{*}<3.3\right)$.

Thermocycling was performed to simulate the oral condition as Ferracane et al declared that composites when subjected to oral environment showed degradation of the outer surface and subsurface of the material, leading to microfractures, which create easier pathways for the staining substances to penetrate. ${ }^{35,36}$ In the current study, thermocycling had a non-significant color change between two tested groups which was not precipitable $\left(\Delta \mathrm{E}^{*}<3.3\right)$. This was in accordance with Lee et al who concluded that the color change after thermocycling was negligible $\left(\Delta E^{*}=0.4-1.3\right){ }^{37,38}$ However, Hahnel et al mentioned that the artificial ageing had a significant negative effect on dental composite properties. ${ }^{39}$ They also stated that the ageing time was more critical than the ageing medium..$^{39}$

For the CAD/CAM composite resin, it was shown that it had more resistance to staining with all mouth rinse solutions in comparison to nanohybrid composite, this explained by its processing and polymerization procedure during manufacturing and its greater crosslinking which decreased the porosity defects and the homogenous polymerization during the industrial phase. ${ }^{40-42}$ On the other hand, Arocha et al noted a higher stainability of CAD/CAM composite resins when compared with laboratory processed ones. ${ }^{43}$ Also the same results were found in other study evaluating CAD/CAM processed composites versus direct composites.$^{40}$ Furthermore, 
the poor aesthetic and mechanical properties of the $\mathrm{CAD} / \mathrm{CAM}$ processed composites were reported. ${ }^{44,45}$

Regardless of the mouth rinse solution, nanohybrid veneering composite (C group) recorded significantly a higher color change value than HIPC ( $\mathrm{H}$ group) and this could be explained by different material compositions, but it was still unperceivable clinically $\left(\Delta \mathrm{E}^{*}<3.3\right)$. Crea.lign is $50 \%$ nanoceramic filler composite structure that is considered to provide the optimal stability as ceramic materials do not exhibit any water absorption and, therefore, no dye molecules can penetrate into the surface. ${ }^{21,22}$ As crea.lign is a nanohybrid composite, it was supposed to be more resistant to water sorption by incorporated nanoparticles where composites with larger filler particles are more susceptible to water sorption as well as the effect of coloring agents on the bond quality between the matrix and filler can cause discoloration. ${ }^{46}$ In addition, it was found that the performance of composites in the aquas environment like oral cavity or mouth rinse solutions is depending on the filler particles distributions in the polymer network as the uniform distribution of such fillers that were supposed to be better for nanohybrid composites minimizes the filler rich and filler depleted areas within the composites which decreases the voids or the spaces of nonbonding at the filler/matrix interface and this decreases the water sorption and increases the discoloration resistance. ${ }^{47,48}$

However, the staining susceptibility of crea.lign composite might be related to the filler, resin and staining agent types. ${ }^{23}$ This was in agreement with other study that found a higher color difference for nanocomposites than microhybrid ones after staining. ${ }^{24}$ Also, less color change with increased particle size was reported as the of organic filler/ matrix proportion decreased. ${ }^{25}$

Water absorption may be a sign of color change of composite resins as the degree of water absorption of composite materials is directly affecting their response to accept staining. ${ }^{21}$ In addition, the hydrophobic or hydrophilic nature of the resin matrix determines the degree of the stainability. It was found that hydrophilic materials are more susceptible to discoloration than hydrophobic materials when immersed in coloring solution. ${ }^{4}$ Also, the chemical composition of the consumed food has a prime concern as it contains water soluble pigments that can be also absorbed by composite resins of hydrophilic resin matrix leading to composite discoloration..$^{2,5,8,15,29,30}$ Moreover, the resinous matrix composition affects the water sorption of the composite resins..$^{21,49}$ Previous studies evidenced a noticeable increase of the water uptake in bisphenol A-glycidyl methacrylate (bisGMA) based resins from 3-6\% when compared to triethylen glycol dimethacrylate (TEGDMA) which increases from $0-1 \% .^{50}$ It was also reported that urethane-dimethacrylate (UDMA) based composite resins showed better staining resistance and less water sorption under normal curing conditions, than other dimethacrylates in their resin matrix. ${ }^{51,52}$ Since the matrix of CAD/CAM composites is based on UDMA and TEGDMA, while the matrix of direct and indirect composites is based on BisGMA that results in their higher water sorption allowing the water and hydrophilic colorants to penetrate the resin matrix and explains the findings in this study. ${ }^{53,54}$

Chlorhexidine (CHX) has recorded a discoloration effect on oral tissues and dental restorations, this effect is exaggerated when combined with dietary factors.$^{55}$ In the current study, Hexitol showed unpreciptible color changes. This was in agreement with Lee et al who declared that the color difference values were within the acceptable range for the evaluated esthetic restorative materials after immersion in mouth rinses $\left(\Delta \mathrm{E}^{*}<3.3\right) .{ }^{56}$ It was also noted by Fay et al that chlorhexidine and water did not promote perceivable color changes. ${ }^{57} \mathrm{On}$ the other hand, several previous studies reported a perceptible discoloration of composite resins by 
$\mathrm{CHX}(\Delta \mathrm{E}>3.3){ }^{58-60}$ The reported higher staining of the specimens in the those studies compared to this research might be assigned to the immersion duration in CHX, CHX concentration, and different tested restorative materials. For H group, Hexitol showed statistically significant color change, this might be due to the alcohol concentration in the mouth rinse that affects the composite microhardness and leads to the discoloration.

In this study, despite the low $\mathrm{pH}$ of alcohol-free Listerine $(\mathrm{pH}=3.7)$, it showed greater discoloration than other mouth rinses with crea.lign composite. This could be explained by the effect of low $\mathrm{pH}$ of solution on the roughness of the composite resins that cause discoloration. ${ }^{62}$ This was in agreement with Gürgan et al who stated alcohol-containing and alcohol-free mouth rinses could have an influence on the hardness of composite materials. ${ }^{61}$ This means more surface roughness that might lead to discoloration. While it was not found a correlation between $\mathrm{pH}$ and discoloration of HIPC composite, which is in accordance with the findings of Diab et al, who reported that the $\mathrm{pH}$ of test solutions did not have an effect on discoloration of restorative materials. $^{63}$

In the current study, after immersion in Distilled Water, no perceptible color change was found with both composite resins but lower than was obtained by chlorohexidine and Listerine. This was not in agreement with Lee et al and Gürdal et al who found more color change after immersion in distilled water than that obtained with chlorhexidine-containing and other mouthrinses. ${ }^{56,64}$

One of the limitations of the current study is the in vitro testing, where some extent intraoral simulation was carried out focusing on the individual discoloration effects of each rinse. Many other factors can affect color where being emphasized that they were isolated or associated, such aspresence of saliva, poor prosthesis cleaning, ${ }^{65-68}$ oral environment particles ${ }^{64,69}$ fabrication technique effect on material porosity, ${ }^{70,71}$ material surface flaws, ${ }^{64,71}$ and surface polishing may affect the color stability of composite resins. ${ }^{72}$ In addition, interference between the illuminant and the color sensor of the spectrophotometer leads to edge loss error. ${ }^{71}$ Further in vivo studies for better correlation with the clinical setting should be carried out. The chemical interactions between coloring agents and composite resins should be also evaluated.

\section{CONCLUSIONS}

There were color changes in tested HIPC and nanohybrid composite veneered PEEK crowns after thermocycling and immersion in different mouth resin solutions. However, the color difference was within the clinically acceptable range $\left(\Delta \mathrm{E}^{*}<3.3\right)$.

\section{REFERENCES}

1. Stawarczyk B, Beuer F, Wimmer T, Jahn D, Sener B, Roos M, Schmidlin PR. Polyetheretherketone-a suitable material for fixed dental prostheses?. Journal of Biomedical Materials Research Part B: Applied Biomaterials. 2013 Oct;101(7):1209-16.

2. Stawarczyk B, Jordan P, Schmidlin PR, Roos M, Eichberger M, Gernet W, Keul C. PEEK surface treatment effects on tensile bond strength to veneering resins. The Journal of Prosthetic Dentistry. 2014 Nov 1;112(5):1278-88.

3. Uhrenbacher J, Schmidlin PR, Keul C, Eichberger M, Roos M, Gernet W, Stawarczyk B. The effect of surface modification on the retention strength of polyetheretherketone crowns adhesively bonded to dentin abutments. The Journal of prosthetic dentistry. 2014 Dec 1; 112(6):1489-97.

4. Kumari RV, Nagaraj H, Siddaraju K, Poluri RK. Evaluation of the effect of surface polishing, oral beverages and food colorants on color stability and surface roughness of nanocomposite resins. Journal of international oral health: JIOH. 2015 Jul;7(7):63.

5. Faiez N, Muawia A, Qudeimat AS. Al-Rimawi. Dental Discolouration: An Overview. J Esthet Restor Dent. 1999;11(6):291-310.

6. Addy M, Mahdavi SA, Loyn T. Dietary staining in vitro by mouthrinses as a comparative measure of antiseptic activity and predictor of staining in vivo. Journal of Dentistry. 1995 Apr 1;23(2):95-9. 
7. Cengiz S, Yüzbaşioğlu E, Cengiz MI, Velioğlu N, Sevimli G. Color Stability and Surface Roughness of a LaboratoryProcessed Composite Resin as a Function of Mouthrinse. Journal of Esthetic and Restorative Dentistry. 2015 Sep;27(5):314-21.

8. Fairchild MD. Color appearance models and complex visual stimuli. Journal of Dentistry. 2010 Jan 1;38:e25-33.

9. Goodacre CJ, Campagni WV, Aquilino SA. Tooth preparations for complete crowns: an art form based on scientific principles. The Journal of prosthetic dentistry. 2001 Apr 1;85(4):363-76.

10. Beleidy M, Ziada A. Scanning electron microscope evaluation of the marginal gap and internal fit of additive versus subtractive fabrication techniques for posterior lithium disilicate crowns. Egyptian Dental Journal. 2019 Jul 1;65(3-July (Fixed Prosthodontics, Dental Materials, Conservative Dentistry \& Endodontics)):2779-93.

11. Shakal MA. Comparative Fracture Resistance of Composite Veneered Polyether Ether Ketone Crowns with Ceramic and Composite Veneered Zirconia Crowns. Egyptian Dental Journal. 2018 Jan 1;64(1-January (Fixed Prosthodontics, Dental Materials, Conservative Dentistry \& Endodontics)):711-9.

12. Wyzecki G, Stiles WS. Color science. Concepts and Methods, Quantitative Data and Formulae. 1982;2.

13. Ceci M, Viola M, Rattalino D, Beltrami R, Colombo M, Poggio C. Discoloration of different esthetic restorative materials: A spectrophotometric evaluation. European journal of dentistry. $2017 \mathrm{Apr} ; 11(2): 149$.

14. Uchida H, Vaidyanathan J, Viswanadhan T, Vaidyanathan TK. Color stability of dental composites as a function of shade. The Journal of prosthetic dentistry. 1998 Apr 1;79(4):372-7.

15. Arocha MA, Basilio J, Llopis J, Di Bella E, Roig M, Ardu S, Mayoral JR. Colour stainability of indirect CADCAM processed composites vs. conventionally laboratory processed composites after immersion in staining solutions. Journal of dentistry. 2014 Jul 1;42(7):831-8.

16. Ertas E, Gueler AU, Yuecel AC, Koepruelue H, Gueler E. Color stability of resin composites after immersion in different drinks. Dental materials journal. 2006;25(2):3716.

17. Topcu FT, Sahinkesen G, Yamanel K, Erdemir U, Oktay EA, Ersahan S. Influence of different drinks on the colour stability of dental resin composites. European journal of dentistry. 2009 Jan;3(1):50.

18. Arocha MA, Mayoral JR, Lefever D, Mercade M, Basilio J, Roig M. Color stability of siloranes versus methacrylatebased composites after immersion in staining solutions. Clinical oral investigations. 2013 Jul 1;17(6):1481-7.

19. Ardu S, Braut V, Gutemberg D, Krejci I, Dietschi D, Feilzer AJ. A long-term laboratory test on staining susceptibility of esthetic composite resin materials. Quintessence International. 2010 Sep 1;41(8).

20. Dietschi D, Campanile G, Holz J, Meyer JM. Comparison of the color stability of ten new-generation composites: an in vitro study. Dental Materials. 1994 Nov 1;10(6):353-62.

21. Bagheri R, Burrow MF, Tyas M. Influence of foodsimulating solutions and surface finish on susceptibility to staining of aesthetic restorative materials. Journal of dentistry. 2005 May 1;33(5):389-98.

22. Nguyen JF, Migonney V, Ruse ND, Sadoun M. Properties of experimental urethane dimethacrylate-based dental resin composite blocks obtained via thermo-polymerization under high pressure. Dental materials. 2013 May 1;29(5):535-41.

23. Llena C, Lozano E, Amengual J, Forner L. Reliability of two color selection devices in matching and measuring tooth color. J Contemp Dent Pract. 2011 Jan 1;12(1):19-23.

24. Nasim I, Neelakantan P, Sujeer R, Subbarao CV. Color stability of microfilled, microhybrid and nanocomposite resins - an in vitro study. Journal of Dentistry. 2010 Jan 1;38:e137-42.

25. Ardu S, Gutemberg D, Krejci I, Feilzer AJ, Di Bella E, Dietschi D. Influence of water sorption on resin composite color and color variation amongst various composite brands with identical shade code: an in vitro evaluation. Journal of dentistry. 2011 Jul 1;39:e37-44.

26. Lee YK, Yu B, Lim HN, Lim JI. Difference in the color stability of direct and indirect resin composites. Journal of Applied Oral Science. 2011 Apr;19(2):154-60.

27. Nakazawa M. Color stability of indirect composite materials polymerized with different polymerization systems. Journal of oral science. 2009;51(2):267-73.

28. Koller M, Arnetzl GV, Holly L, Arnetzl G. Lava ultimate resin nano ceramic for $\mathrm{CAD} / \mathrm{CAM}$ : customization case study. International journal of computerized dentistry. 2012 Jan 1;15(2):159-64. 
29. Paul S, Peter A, Pietrobon N, Hämmerle CH. Visual and spectrophotometric shade analysis of human teeth. Journal of dental research. 2002 Aug;81(8):578-82.

30. Khurana R, Tredwin CJ, Weisbloom M, Moles DR. A clinical evaluation of the individual repeatability of three commercially available colour measuring devices. British dental journal. 2007 Dec;203(12):675-80.

31. Ardu S, Braut V, Di Bella E, Lefever D. Influence of background on natural tooth colour coordinates: an in vivo evaluation. Odontology. 2014 Jul 1;102(2):267-71.

32. Samra AP, Pereira SK, Delgado LC, Borges CP. Color stability evaluation of aesthetic restorative materials. Brazilian oral research. 2008 Sep;22(3):205-10.

33. Fontes ST, Fernández MR, Moura CM, Meireles SS. Color stability of a nanofill composite: effect of different immersion media. Journal of Applied Oral Science. 2009 Oct;17(5):388-91.

34. Kuehni RG, Marcus RT. An experiment in visual scaling of small color differences. Color Research \& Application. 1979 Jun;4(2):83-91

35. Hunter RS, Harold RW. The measurement of appearance. John Wiley \& Sons; 1987 Sep 8.

36. Ferracane JL, Moser JB, Greener EH. Ultraviolet lightinduced yellowing of dental restorative resins. Journal of Prosthetic Dentistry. 1985 Oct 1;54(4):483-7.

37. Furuse AY, Gordon K, Rodrigues FP, Silikas N, Watts DC. Colour-stability and gloss-retention of silorane and dimethacrylate composites with accelerated aging. Journal of Dentistry. 2008 Nov 1;36(11):945-52.

38. Lee Y, Lim B, Rhee S, Yang H, Powers JM. Color and translucency of A2 shade resin composites after curing, polishing and thermocycling. OPERATIVE DENTISTRYUNIVERSITY OF WASHINGTON-. 2005 Aug;30(4):436.

39. Lee YK, Lim BS, Rhee SH, Yang HC, Powers JM. Changes of optical properties of dental nano-filled resin composites after curing and thermocycling. Journal of Biomedical Materials Research Part B: Applied Biomaterials: An Official Journal of The Society for Biomaterials, The Japanese Society for Biomaterials, and The Australian Society for Biomaterials and the Korean Society for Biomaterials. 2004 Oct 15;71(1):16-21.

40. Hahnel S, Henrich A, Bürgers R, Handel G, Rosentritt M. Investigation of mechanical properties of modern dental composites after artificial aging for one year. Operative Dentistry. 2010 Jul;35(4):412-9.
41. Stawarczyk B, Sener B, Trottmann A, Roos M, Oezcan $\mathrm{M}$, Haemmerle $\mathrm{CH}$. Discoloration of manually fabricated resins and industrially fabricated CAD/CAM blocks versus glass-ceramic: effect of storage media, duration, and subsequent polishing. Dental materials journal. 2012;31(3):377-83.

42. Fasbinder DJ, DENNISON JB, HEYS DR, LAMPE K. The clinical performance of CAD/CAM-generated composite inlays. The Journal of the American Dental Association. 2005 Dec 1;136(12):1714-23.

43. Mainjot AK, Dupont NM, Oudkerk JC, Dewael TY, Sadoun MJ. From artisanal to CAD-CAM blocks: state of the art of indirect composites. Journal of dental research. 2016 May;95(5):487-95.

44. Arocha MA, Basilio J, Llopis J, Di Bella E, Roig M, Ardu S, Mayoral JR. Colour stainability of indirect CADCAM processed composites vs. conventionally laboratory processed composites after immersion in staining solutions. Journal of dentistry. 2014 Jul 1;42(7):831-8.

45. Nguyen JF, Migonney V, Ruse ND, Sadoun M. Resin composite blocks via high-pressure high-temperature polymerization. Dental materials. 2012 May 1;28(5): 529-34.

46. Rocca GT, Bonnafous F, Rizcalla N, Krejci I. A technique to improve the esthetic aspects of CAD/CAM composite resin restorations. The Journal of prosthetic dentistry. 2010 Oct 1;104(4):273-5.

47. Manabe A, Kato Y, Finger WJ, Kanehira M, Komatsu M. Discoloration of coating resins exposed to staining solutions in vitro. Dental materials journal. 2009;28(3):338-43.

48. Skrtic D, Antonucci JM, McDonough WG, Liu DW. Effect of chemical structure and composition of the resin phase on mechanical strength and vinyl conversion of amorphous calcium phosphate-based composites. Journal of Biomedical Materials Research Part A. 2004 Mar 15;68(4):763-72.

49. de Gee AJ, ten Harkel-Hagenaar E, Davidson CL. Color dye for identification of incompletely cured composite resins. Journal of Prosthetic Dentistry. 1984 Nov 1;52(5):626-31.

50. Kalachandra S, Turner DT. Water sorption of polymethacrylate networks: Bis-GMA/TEGDM copolymers. Journal of Biomedical Materials Research. 1987 Mar; 21(3):329-38.

51. Kugel G. Direct and indirect adhesive restorative materials: a review. American journal of dentistry. 2000 Nov;13(Spec No):35D. 
52. Moszner N, Fischer UK, Angermann J, Rheinberger V. A partially aromatic urethane dimethacrylate as a new substitute for Bis-GMA in restorative composites. Dental Materials. 2008 May 1;24(5):694-9.

53. Sideridou I, Tserki V, Papanastasiou G. Effect of chemical structure on degree of conversion in light-cured dimethacrylate-based dental resins. Biomaterials. 2002 Apr 1;23(8):1819-29.

54. Sideridou ID, Karabela MM. Sorption of water, ethanol or ethanol/water solutions by light-cured dental dimethacrylate resins. dental materials. 2011 Oct 1;27(10): 1003-10.

55. Miranda Dde A, Bertoldo CE, Aguiar FH, Lima DA, Lovadino JR. Effects of mouthwashes on Knoop hardness and surface roughness of dental composites after different immersion times. Braz Oral Res. 2011;25(2): 168-173.

56. Lee YK, El Zawahry M, Noaman KM, Powers JM. Effect of mouthwash and accelerated aging on the color stability of esthetic restorative materials. American journal of dentistry. 2000 Jun;13(3):159.

57. Fay RM, Servos T, Powers JM. Color of restorative materials after staining and bleaching. Operative Dentistry. 1999;24(5):292.

58. Turgut S, Bagis B, Ayaz EA, Ulusoy KU, Altintas SH, Korkmaz FM, Bagis N. Discoloration of provisional restorations after oral rinses. International journal of medical sciences. 2013;10(11):1503.

59. Baig AR, Shori DD, Shenoi PR, Ali SN, Shetti S, Godhane A. Mouthrinses affect color stability of composite. Journal of conservative dentistry: JCD. 2016 Jul;19(4):355.

60. Ahrari F, Eslami N, Zamani R. The Effect of Mouthrinses Containing Metal Nanoparticles on Color Stability of Composite Resin. Journal of Mashhad Dental School. 2015;39(1):1-8.

61. Gürgan S, Önen A, Köprülü H. In vitro effects of alcoholcontaining and alcohol-free mouthrinses on microhardness of some restorative materials. Journal of oral rehabilitation. 1997 Mar;24(3):244-6.

62. Villalta P, Lu H, Okte Z, Garcia-Godoy F, Powers JM. Effects of staining and bleaching on color change of dental composite resins. The Journal of prosthetic dentistry. 2006 Feb 1;95(2):137-42.
63. Diab M, Zaazou MH, Mubarak EH, Olaa MI. Effect of five commercial mouthrinses on the microhardness and color stability of two resin composite restorative materials. Aust J Basic Appl Sci. 2007;1(4):667-74.

64. Gürdal P, Akdeniz BG, Hakan Sen B. The effects of mouthrinses on microhardness and colour stability of aesthetic restorative materials. Journal of oral rehabilitation. 2002 Sep;29(9):895-901.

65. Goiato MC, Zuccolotti BC, Moreno A, dos Santos DM, Pesqueira AA, de Carvalho Dekon SF. Colour change of soft denture liners after storage in coffee and coke. Gerodontology. 2011 Jun;28(2):140-5.

66. Imirzalioglu P, Karacaer O, Yilmaz B, Ozmen MSc I. Color stability of denture acrylic resins and a soft lining material against tea, coffee, and nicotine. Journal of Prosthodontics: Implant, Esthetic and Reconstructive Dentistry. 2010 Feb;19(2):118-24.

67. Waliszewski M. Restoring dentate appearance: a literature review for modern complete denture esthetics. The Journal of prosthetic dentistry. 2005 Apr 1;93(4):386-94.

68. Heydecke G, Locker D, Awad MA, Lund JP, Feine JS. Oral and general health-related quality of life with conventional and implant dentures. Community dentistry and oral epidemiology. 2003 Jun;31(3):161-8.

69. Knott NJ. The durability of acrylic complete denture bases in practice. Quintessence international (Berlin, Germany: 1985). 1989 May;20(5):341.

70. Colucci V, Dos Santos CD, AMARAL FL, CORONA SA, CATIRSE AB. Influence of $\mathrm{NaHCO} 3$ powder on translucency of microfilled composite resin immersed in different mouthrinses. Journal of Esthetic and Restorative Dentistry. 2009 Aug;21(4):242-8.

71. Keyf F, Etikan İ. Evaluation of gloss changes of two denture acrylic resin materials in four different beverages. Dental materials. 2004 Mar 1;20(3):244-51.

72. Cavalcanti AN, Mitsui FH, Ambrosano GM, Mathias P, Marchi GM. Effect of different mouthrinses on Knoop hardness of a restorative composite. American journal of dentistry. 2005 Dec;18(6):338 